\title{
Competencias directivas en la gestión universitaria en Colombia
}

\section{Cristian Bedoya Dorado}

https://orcid.org/0000-0001-9609-0319 Universidad del Valle, Colombia bedoya.cristian@correounivalle.edu.co

\section{Guillermo Murillo Vargas}

https://orcid.org/0000-0003-2268-598X Universidad del Valle, Colombia guillermo.murillo@correounivalle.edu.co

\section{Carlos Hernán González Campo}

https://orcid.org/0000-0003-2120-8209 Universidad del Valle, Colombia

carlosh.gonzalez@correounivalle.edu.co

\section{Resumen}

El objetivo de esta investigación es identificar en la percepción de los directivos cuál es el grado de identificación con una serie de competencias en la gestión de sus cargos. El estudio contrasta los resultados según posición jerárquica, género y tipo de institución (pública y privada) de afiliación. El estudio se desarrolló con un enfoque cuantitativo descriptivo y la información se recolectó por medio de un cuestionario con una escala tipo Likert, aplicada a una muestra no probabilistica de 272 directivos en Colombia, de diferentes instituciones de educación superior. Se encontró que las competencias con mayor grado de correspondencia son el trabajo en equipo y el liderazgo.

\section{Palabras claves (Fuente: tesauro de la Unesco)}

Educación superior; enseñanza superior; competencias directivas; gerencia educativa; gestión universitaria; liderazgo educativo. 


\title{
Managerial Skills for University Management in Colombia
}

\begin{abstract}
This research aims to identify, from managers' perception, their degree of identification with a series of skills required by their positions. The study contrasts the results by hierarchical position, gender, and university type (public and private). It is conducted from a descriptive quantitative approach. For data collection, we used a questionnaire with a Likert scale applied to a non-probabilistic sample of 272 managers in Colombia from different higher education institutions. We found that the skills with the highest degree of correspondence are teamwork and leadership.
\end{abstract}

\section{Keyword (Source: Unesco Thesaurus)}

Higher education; university education; educational management; university management; managerial qualifications; educative leadership. 


\section{Competências gerenciais na gestão universitária na Colômbia}

Resumo

O objetivo desta pesquisa é identificar, sob a percepção dos líderes, qual o grau de identificação com uma série de competências na gestão de seus cargos. Este estudo compara os resultados segundo a posição hierárquica, o gênero do líder e o tipo de instituição (pública ou privada) de afiliação. Foi desenvolvido sob uma abordagem quantitativa descritiva. A informação foi coletada por meio de um questionário com escala tipo Likert, aplicado a uma amostra não probabilística de 272 diretores na Colômbia, de diferentes instituições do ensino superior. Foi constatado que as competências com maior grau de correspondência são o trabalho em equipe e a liderança.

\section{Palavras-chave (Fonte: tesauro da Unesco)}

Educação superior; ensino superior; gestão educacional; gestão universitária; habilidades gerenciais; liderança educacional. 
Las reformas de la educación superior en Colombia y en otros países latinoamericanos no solo se han derivado de las políticas del neoliberalismo, sino que se enmarcan en el paradigma de la nueva gestión pública (NGP) (Balbachevsky, 2015). Esto ha establecido una agenda que ha configurado las instituciones de educación superior (IES) generando roles y funciones diferentes, transformando identidades, culturas y conductas, y las relaciones entre los actores cotidianos, así como con los actores emergentes (Shams, 2019; Whitchurch, 2013). Esta condición refleja una tendencia del panorama global en el que la literatura académica ha evidenciado un énfasis en la eficiencia y la calidad desde las IES, muy cercano al de las organizaciones productivas (Aguilar, 2006; López, 2005).

El paradigma de la NGP tiene sus orígenes en los años ochenta del siglo XX en el contexto de las reformas administrativas de orientación neoliberal en instituciones públicas de Inglaterra y los Estados Unidos, donde se propuso como principios centrales la economía, la eficiencia y la eficacia para la administración pública, con lo que se buscó satisfacer de esta manera las aspiraciones públicas (Barzelay, 2003). Esto ha implicado una orientación hacia los resultados, la innovación, la planeación estratégica, la administración por logros, la gestión financiera, el control de la gestión y los indicadores, etc., que reflejan la aplicación de las dinámicas del ámbito privado en lo público (Aguilar, 2006).

De acuerdo con López (2005), esta transformación ha impulsado la incorporación de técnicas para el desarrollo de habilidades directivas, como liderazgo, negociación, toma de decisiones, manejo del conflicto, gestión de equipos, gestión de la innovación, gestión de la incertidumbre, entre otras. No obstante, esto no solo significa el cambio de identidades y roles de actores académicos, sino, además, la emergencia de nuevos roles que son asumidos por actores que propiamente no provienen del contexto universitario ni académico (Henkel, 2000).
Algunas investigaciones distinguen dos tipos de directivos, de acuerdo con las referencias al Académico Directivo (Manager-Academic) o al Directivo Académico (Academic-Manager), donde el primero abarca a los profesores o investigadores que asumen cargos directivos en universidades, cuyas creencias están centradas en el profesionalismo, el conocimiento y la autonomía profesional (Bedoya et al., 2020; Castro y Tomàs, 2011; Deem, 2003; Winter, 2009), mientras que el segundo agrupa a los sujetos que asumen roles directivos en instituciones de educación superior con modelos corporativos gerenciales, y sus trayectorias proceden del sector productivo (Blenkinsopp y Stalker, 2004; Hellawell y Hancock, 2001). Así mismo, otras investigaciones referencian a los Profesionales de Educación Superior (High Education Professionals), "Paraacadémicos" o Tercer Espacio como nuevos roles en la dirección universitaria (McFarlane, 2011; Schneijderberg y Merkator, 2013; Whitchurch, 2013).

Los roles directivos implican, a su vez, una transición de un rol profesional o académico hacia uno de poder y gestión en la administración de universidades. Esta transición, además de configurar identidades e interacciones (Blenkinsopp y Stalker, 2004; Whitchurch, 2013), trae ambivalencia entre el rol de profesional o académico y el de directivo universitario, que se dan en espacios temporales diversos, con requerimientos y exigencias específicos (Correia et al., 2017). Para el caso del rol del directivo universitario, este se ve influenciado por el ejercicio de sus funciones, la dinámica organizacional y las demandas del contexto externo. Así mismo, el modo de desempeñar este rol se determina por las características, comportamientos y actitudes del directivo, que pueden generar una incidencia positiva o negativa en el devenir de las instituciones (Correia et al., 2017; Knox et al., 2019).

Lo anterior ha llevado a diversos investigadores a explorar las habilidades, conocimientos y características necesarias para desempeñar los cargos administrativos en el sector de la educación superior 
y también los comportamientos que tienen mayor impacto en el desempeño y efectividad de sus resultados (Knox et al., 2019; Rehbock, 2020; Shahmandi et al., 2011; Shams, 2019; Spendlove, 2007; Whitchurch, 2013). La literatura ha dado respuesta a estos interrogantes con la noción de "competencia", que gira en torno a la acción y el conocimiento y agrupa habilidades, destrezas, aptitudes, dominios, idoneidad, atribuciones y características de las personas que permiten aumentar el nivel de su desempeño y demostrarlo (Casani y Rodríguez, 2012; Charria et al., 2011; Loyola y Tristá, 2017).

En Colombia, el ejercicio de las directivas de las IES, además del proceso de elección de las mismas, ha estado mediado principalmente por la Ley 30 de 1992, la cual organiza el servicio público de la educación superior (Congreso de la República de Colombia, 1992), así como por la normatividad de inspección y vigilancia y la de aseguramiento de la calidad, que incluye, entre otros, los lineamientos del Consejo Nacional de Acreditación sobre los procesos de acreditación de alta calidad de programas e instituciones, entre otros (CNA, 2020). No obstante, existen otros elementos vinculados con la autonomía de las instituciones, así como variables contingentes que inciden en los roles y funciones de los directivos universitarios.

Con relación a los requisitos y las competencias para ocupar estos cargos, el Ministerio de Educación Nacional (MEN) resolvió la adopción e incorporación del Manual de Funciones, Requisitos y Competencias "para los cargos directivos docentes y docentes del sistema especial de carrera docente" en la Resolución 09317 de 2016. Así mismo, existen algunos lineamientos del Departamento de la Función Pública guiados por el Decreto 1083 de 2015 que inciden en los roles y requisitos de los directivos universitarios (Presidencia de la República, 2020).

Las investigaciones sobre este tema en el contexto colombiano son escasas y las existentes se concentran en competencias específicas, como el caso del liderazgo (Pérez et al., 2016; Vargas y García, 2017). Las transformaciones del sector de la educación superior en Colombia, sumadas a la escasez de estudios sobre el directivo universitario contemporáneo, ponen de manifiesto la necesidad de investigar las características de la gestión de este tipo de directivos que les permiten hacer frente a los retos y desafíos que enfrentan en el sector, lo que tiene implicaciones en la generación de programas para la formación en gestión universitaria, la redefinición de lineamientos por parte del gobierno nacional con relación a requisitos para directivos del sector de la educación y el análisis y diseño de cargos de dirección en las instituciones del sector.

De acuerdo con lo anterior, el presente estudio tiene como objetivo identificar, según la percepción de los directivos universitarios en Colombia, cuál es el grado de identificación con una serie de competencias en la gestión de sus cargos y cómo contrastan dichas valoraciones de acuerdo con la posición jerárquica, el género del directivo y el tipo de institución (pública y privada). El proceso de investigación fue realizado mediante un enfoque cuantitativo descriptivo y se utilizó como técnica de recolección de la información el cuestionario. La estructura del artículo corresponde a cuatro apartados: primero, la revisión de la literatura sobre competencias en la dirección universitaria, seguida del diseño metodológico y los resultados, que son descritos e interpretados, para, finalmente, dar las conclusiones y señalar la contribución empírica del estudio.

\section{Revisión de la literatura}

La noción de competencia se desarrolla desde la década de 1920 en Argentina, Australia, los Estados Unidos y países europeos como Alemania e Inglaterra (Charria et al., 2011). En los contextos laborales se reconoce que son los trabajos de David McClelland (1973) los que permitieron la elaboración de constructos para su análisis, mediante la identificación de niveles de desempeño asociados a comportamientos y la disposición de los suje- 
tos, lo que recoge, a su vez, los aportes de la teoría de la motivación de este autor. La noción ha tenido diferentes significados y aplicaciones $y$, por sus orígenes, se ha expresado en términos de comportamientos de los individuos o como estándares mínimos de desempeño. En algunas definiciones, las competencias son atributos subyacentes de los sujetos, lo que agrupa sus conocimientos, habilidades y destrezas, que permiten las actuaciones y el desempeño. Esto, a su vez, ha nutrido el campo de la educación, ya que las competencias darían cuenta de los insumos necesarios para definir y desarrollar programas de aprendizaje y, asimismo, gestionar y mejorar el desempeño humano en otros ámbitos, como los laborales, a través de la formación y entrenamiento (Hoffmann, 1999).

En el ámbito laboral y profesional, las aproximaciones a esta noción son diversas y comparten elementos en común, como los niveles del saber (conocimiento especializado y de la ejecución de tareas orientadas a las actividades laborales), saber hacer (capacidad de dar respuesta sistemática a requerimientos laborales o la aplicación del conocimiento), saber ser (disponibilidad para el trabajo en equipo, la comunicación, la cooperación, etc.), y saber estar (capacidad para asumir las responsabilidades y deberes, organizar y decidir sobre cuestiones de trabajo), todo ello en relación con la acción y el conocimiento (Alles, 2007; Boyatzis, 1982; Charria et al., 2011; LevyLeboyer, 2002).

Para la Organización Internacional del Trabajo (OIT, 1993), las competencias laborales implican la capacidad o habilidad para desarrollar tareas y deberes específicos para llevar a cabo una actividad de manera exitosa. Estas capacidades o habilidades se evidencian en el comportamiento y las conductas, por lo que los conocimientos y saberes se combinan con elementos de la aptitud, actitud, rasgos de personalidad y disposición (Alles, 2007; Levy-Leboyer, 2002).

Las competencias han sido clasificadas en diferentes tipologías, a partir de sus atributos o carac- terísticas, como: la motivación, los conocimientos, las habilidades, las características individuales, etc.; según las similitudes de las competencias para su ámbito de aplicación (generales, transversales, específicas, etc.), en relación con los niveles del saber, hacer, ser, estar, etc.; según el contexto de aplicación y las ocupaciones (académicas, profesionales y laborales); o a partir de rasgos comportamentales y funcionales (Alles, 2007; Charria et al., 2011). Estas clasificaciones han calado en los organismos nacionales e internacionales (MEN, 2016; OIT, 1993), los cuales, bajo los aportes teóricos de las investigaciones, han definido competencias para contextos de aplicación.

Para el caso de los requisitos y competencias de directivos universitarios, el MEN, siguiendo la orientación del Departamento Administrativo de la Función Pública, distingue entre competencias funcionales y comportamentales. Por una parte, las funcionales corresponden a las habilidades específicas que se requieren para desempeñar un cargo, como la dirección, planeación, coordinación, administración, orientación, etc., mientras que las comportamentales se asocian a las actitudes, valores, objetivos, motivaciones, características de la personalidad, etc., que soportan las tareas para el cargo (MEN, 2016).

Desde el punto de vista académico, existen definiciones de competencias directivas, como la señalada por Hellriegel et al. (2017), quienes consideran que comprenden los conocimientos, habilidades, comportamientos y actitudes necesarios para ser eficiente en diferentes actividades y en distintas organizaciones en los puestos de dirección. Así mismo, las competencias directivas se han explorado en función del ciclo administrativo, lo que involucra la planeación, organización, dirección y control.

En educación superior, las investigaciones sobre competencias se han orientado hacia cuatro líneas: 1) los estudios sobre las principales competencias de los directivos universitarios, 2) las diferencias de las competencias según los cargos directivos, 3 ) 
las competencias según la afiliación institucional, principalmente las críticas sobre la gestión pública, y 4) las diferencias de las competencias según el género del directivo.

En la primera línea de investigación, se concentran la mayoría de las publicaciones. Ejemplo de ello es el trabajo de Zermeño et al. (2014), quienes encuentran en un grupo de directivos universitarios que las competencias más valoradas por estos son: liderazgo, trabajo en equipo, dirección de personas, gestión de recursos e integridad. Otro de los estudios es el de Casani y Rodríguez (2012), en el que se evidencia que las principales competencias para desarrollar las tareas de los directivos universitarios son la confianza en sí mismo (factor de liderazgo), la capacidad para trabajar en equipo y cooperar (factor de dirección de los recursos humanos), la capacidad de impacto e influencia, y la iniciativa (factor de resultados persistentes en las personas).

Potgieter y Coetzee (2010) investigan la relación entre competencias específicas para realizar tareas de directivos y el nivel de entrenamiento requerido para dichas competencias. Los resultados sugieren que para la planeación y organización es importante el liderazgo individual y grupal, la motivación individual y grupal, las habilidades de comunicación, el monitoreo y diseminación de la información, el monitoreo y análisis del ambiente, la gestión de recompensas, y las relaciones con grupos de interés externos. En el caso del liderazgo, se encuentra la necesidad de entrenamiento en implementación de estrategias, gestión del tiempo, liderazgo individual y grupal, la motivación individual y grupal, la delegación de tareas y la gestión de grupos de interés externos. Con relación al control, el estudio muestra que se requiere de liderazgo individual y grupal, motivación individual y grupal, gestión del desempeño, gestión de proyectos, resolución de conflictos y negociación.

Continuando con esta línea, Abdo y Edgar (2019) analizaron las competencias y habilidades de directivos universitarios que soportan los pro- cesos de aprendizaje organizacional en las instituciones de educación superior y encuentran que el liderazgo es una variable moderadora que no solo permite alcanzar este tipo de procesos, sino, además, el desempeño financiero y la gestión del conocimiento. La investigación de Mohd y Dola (2009) encuentra que las principales competencias para los directivos universitarios son la gestión del tiempo y el trabajo en equipo (categoría administración y habilidades de liderazgo), la comunicación y la orientación hacia los resultados (categoría de efectividad personal) y el conocimiento de computación y toma de decisiones (categoría de experticia y competencia profesional).

Rehbock (2020) señala que en la educación superior el liderazgo se ha posicionado como la competencia o habilidad fundamental que requieren sus directivos, debido a los fenómenos cambiantes de sus contextos, la Nueva Gestión Pública y la mayor competencia a nivel internacional. Lo anterior pone de manifiesto que las universidades o instituciones de educación superior requieren liderazgo, no solo en materia de investigación, sino, además, de tipo administrativo.

Telles et al. (2019) investigan cómo en la gestión universitaria se desarrollan muchas actividades de manera improvisada debido a los tipos de estructura de estas instituciones, a la flexibilidad y a la competencia. Según este estudio, las decisiones y acciones de los administradores académicos se caracterizaron por la espontaneidad, la creatividad y la flexibilidad gerencial, con otro tipo de competencias diferentes a las investigadas por otros estudios. Asimismo, para estos autores los entornos dinámicos y complejos que caracterizan la educación superior hacen que las prácticas de improvisación emerjan en el día a día de la gestión académica.

Con relación al desarrollo de las competencias de directivos universitarios, Rybnicek et al. (2019) encuentran en su estudio el efecto positivo que tiene la experiencia previa en la industria o el liderazgo 
en otros sectores para el desarrollo de algunas actividades propias del sector de la educación, como las publicaciones de las áreas de trabajo, la capacidad de adquirir fondos de investigación externos o actividades de emprendimiento, como la comercialización de resultados de investigación a través de patentes. Basados en los resultados, los autores argumentan que la capacidad de investigación adquirida en otros contextos es fundamental para los directivos universitarios debido a que el desempeño científico es un factor clave que caracteriza a las universidades.

Knox et al. (2019) agregan a la gestión de la educación superior la necesidad de las competencias culturales. Según estos autores, este tipo de competencias se asocian a los cambios demográficos y sociales que implican nuevos retos para la pedagogía,y dan cuenta de conductas y capacidades para la aceptación y comprensión de las propias creencias y de otras formas de pensamiento, culturas y cosmovisiones, a las que se suman el conocimiento sobre dichas diferencias culturales y habilidades para trabajar con grupos diversos, etc.

Para el caso de las investigaciones sobre competencias en los distintos cargos directivos universitarios, se han propuesto las clasificaciones de Senior, Middle y Junior para indicar cargos altos, medios y bajos, respectivamente (Mercer, 2009; Mohd y Dola, 2009). Entre estas investigaciones se encuentra la de Pham et al. (2019), quienes encuentran que en los cargos medios de dirección universitaria las principales competencias requeridas son la gestión de cambios y de las tareas administrativas (dominio del liderazgo y administración); la resolución creativa de problemas, las habilidad en presentación y negociación (dominio de consejería y consultoría); la evaluación del desempeño y retroalimentación, coaching y mentoría, la construcción de ambientes de trabajo y la motivación de los miembros de los equipos (dominio de recursos humanos); el mantenimiento de cualidades políticas y éticas, y el autoentrenamiento y la autodirección (dominio de autogestión).
La investigación de Spendlove (2007) en cargos altos de dirección universitaria como rectores, vicerrectores, principales, directores, etc., sugiere que, para el desarrollo de un liderazgo efectivo, los directivos requieren de credibilidad académica y experiencia universitaria. Así mismo, los participantes del estudio señalaron la importancia de la comunicación y la negociación con otros para el liderazgo.

En la tercera línea de investigación se encuentran los trabajos que buscan diferenciar las realidades de los directivos universitarios de las universidades privadas versus las públicas (Deem, 2003; Kloot, 2004; Macarie et al., 2011). Un ejemplo de esta línea es el trabajo de Balyer y Özcan (2017), que evidencia que para los directivos universitarios de instituciones públicas las características más importantes en sus roles interpersonales son la de ser un modelo para sus colegas y usar el carisma y las relaciones humanas; y para la toma de decisiones se encuentra principalmente que los directivos deben ser autoritarios en sus prácticas administrativas; y en el caso de los roles de información, encuentran que los directivos no pueden seguir adecuadamente los cambios de la información.

Finalmente, la última línea de investigación se aborda a la luz de los estudios de género, buscando develar las experiencias de las mujeres en el contexto universitario y sus características como directivas. Esta línea se concentra principalmente en comprender los estilos de liderazgo de las mujeres en comparación con los de los hombres, situando el liderazgo como una competencia. Si bien las investigaciones encuentran baja participación de las mujeres en los cargos de dirección universitaria, apuntan cada vez más a que no existen diferencias significativas cuando se compara su gestión con la de los hombres (Cuadrado et al., 2004; Deem, 2003; Eggins, 2017; Kloot, 2004; Moncayo y Zuluaga, 2015; Tomas et al., 2008; Wallace y Marchant, 2011; Zuluaga y Moncayo, 2014). 


\section{Método}

El estudio se realizó con un enfoque cuantitativo y un diseño no experimental de corte transeccional de tipo exploratorio y descriptivo (Hernández et al., 2014; Méndez, 2006). Esto obedece a que, por una parte, existen pocas investigaciones que den cuenta de cuáles son las competencias más importantes en la dirección universitaria en Colombia y, por otra parte, se pretende identificar y describir dichas competencias en función de las características de los directivos universitarios.

Para el estudio se realizó un muestreo no probabilístico intencional debido a que no existe un total de la población de directivos universitarios en Colombia y porque permite de manera conveniente incluir a participantes que poseen las características que se desea investigar. En este sentido, se invitó a participar en el estudio a un total de 1.134 directivos de diferentes cargos y universidades colombianas, a través de un cuestionario autodirigido online, logrando una tasa de respuesta del 23,9\% $(n=272)$.
El cuestionario online para la recolección de los datos fue construido a partir de una revisión de la literatura sobre competencias administrativas y gerenciales de tipo comportamental y funcional, complementado con variables sociodemográficas para el análisis de las características de los directivos según las competencias. La estructuración de las variables se presenta en la Tabla 1.

\section{Validez y fiabilidad del instrumento}

Para la medición de las variables fueron creados un total de 28 items (4 por cada competencia) con una escala tipo Likert de 5 puntos, que permiten identificar el grado de identificación o aplicación en la gestión de su cargo. El cuestionario contó con la validación por expertos del contenido y de la escala. Por una parte, la validez de contenido está asociada a los elementos definidos por la literatura, que recogen aspectos conceptuales y teóricos. La segunda, a través de la consulta con expertos para verificar, según sus cualificaciones, que el lenguaje de

Tabla 1. Descripción de las variables

\begin{tabular}{|c|c|c|}
\hline Variables & Subvariables & Sustento teórico/empírico \\
\hline $\begin{array}{l}\text { Competencias } \\
\text { comportamentales }\end{array}$ & $\begin{array}{l}\text { - Liderazgo } \\
\text { - Toma de decisiones y negociación } \\
\text { - Trabajo en equipo }\end{array}$ & $\begin{array}{l}\text { (Casani y Rodríguez, 2012; Mohd } \\
\text { y Dola, 2009; Shahmandi et al., } \\
\text { 2011; Zermeño et al., 2014) }\end{array}$ \\
\hline $\begin{array}{l}\text { Competencias } \\
\text { funcionales }\end{array}$ & $\begin{array}{l}\text { - Organización } \\
\text { - Planeación } \\
\text { - Dirección } \\
\text { - Control }\end{array}$ & $\begin{array}{l}\text { (Hellriegel et al., 2017; MEN, } \\
\text { 2016; Potgieter y Coetzee, 2010) }\end{array}$ \\
\hline Sociodemográficas & $\begin{array}{l}\text { Del directivo } \\
\text { - Género: hombre o mujer } \\
\text { - Edad } \\
\text { - Cargos de dirección: } \\
\text { Altos: rector, vicerrector, principal o director, secretario general. } \\
\text { Medios: decanos, vicedecanos, presidentes, homólogos. } \\
\text { Bajos: jefes de departamento, directores de programa, } \\
\text { subdirectores, coordinadores, asesores, líderes, etc. } \\
\text { De la institución } \\
\text { - Antigüedad en el cargo } \\
\text { - Tipo de institución: Pública o Privada } \\
\text { - Número de estudiantes } \\
\text { - Acreditación: Sí o No }\end{array}$ & $\begin{array}{l}\text { (Balyer y Özcan, 2017; Cuadrado } \\
\text { et al., 2004; Deem, 2003; Eggins, } \\
\text { 2017; Mercer, 2009; Mohd y } \\
\text { Dola, 2009; Pham et al., 2019; } \\
\text { Spendlove, 2007; Wallace y } \\
\text { Marchant, 2011) }\end{array}$ \\
\hline
\end{tabular}

Fuente: elaboración propia. 
los ítems fuera comprensible y midiera los temas. En este proceso se consultó a cinco expertos que se incluyeron por tener trayectorias en cargos directivos universitarios y ser académicos del campo de la gestión (administración y organizaciones). A partir de sus observaciones se adecuó la redacción de los ítems, se incluyeron preguntas y se eliminaron otras. Finalmente, para la validación de la escala fue empleado el análisis exploratorio de las cargas fac- toriales, el estadístico de Kaiser-Meyer-Olkin (KMO) y el test de esfericidad de Bartlett. De acuerdo con estos resultados, aquellos ítems que tuvieron las cargas por debajo de 0,7 quedaron excluidos del análisis. Adicional a lo anterior, para la fiabilidad del instrumento, el alfa de Cronbach es evaluado en cada una de las variables. Como resultado, el instrumento agrupa un total 24 ítems, como se presenta en la Tabla 2.

Tabla 2. Validez y fiabilidad del instrumento y las escalas

\begin{tabular}{|c|c|}
\hline Tipo de competencias y competencias & Fiabilidad \\
\hline \multicolumn{2}{|l|}{ Competencias comportamentales } \\
\hline Liderazgo & \multirow[b]{2}{*}{$\begin{array}{l}\text { No. de ítems: } 4 \\
\text { Cronbach } \alpha:, 806 \\
\text { Factorial: } 1 \text { factor } \\
\text { Varianza explicada: } 63,8 \% \\
\text { Sig. Bartlett: , ooo } \\
\text { KMO: } 687\end{array}$} \\
\hline $\begin{array}{l}\text { - Establecimiento de puntos de referencia para la alineación con objetivos de la } \\
\text { universidad. } \\
\text { - Motivación a los seguidores. } \\
\text { - Defensa de creencias, ideas y valores universitarios. } \\
\text { - Orientación e inspiración para la construcción, definición e implementación de } \\
\text { acuerdos pedagógicos, académicos y de convivencia. }\end{array}$ & \\
\hline Toma de decisiones y negociación & \multirow{2}{*}{$\begin{array}{l}\text { No. de items: } 3 \\
\text { Cronbach } \alpha:, 769 \\
\text { Factorial: } 1 \text { factor } \\
\text { Varianza explicada: } 68,5 \% \\
\text { Sig. Bartlett: , 000 } \\
\text { KMO: ,690 }\end{array}$} \\
\hline $\begin{array}{l}\text { - Reconocimiento de las necesidades del otro ante una negociación. } \\
\text { - Desarrollo de alternativas con base en información veraz. } \\
\text { - Búsqueda de estrategias de negociación cuidando las relaciones. }\end{array}$ & \\
\hline Trabajo en equipo & \multirow[b]{2}{*}{$\begin{array}{l}\text { No. de ítems: } 3 \\
\text { Cronbach } \alpha:, 715 \\
\text { Factorial: } 1 \text { factor } \\
\text { Varianza explicada: } 64,0 \% \\
\text { Sig. Bartlett: , 000 } \\
\text { KMO: ,680 }\end{array}$} \\
\hline $\begin{array}{l}\text { - Respeto por los criterios y opiniones de los miembros del equipo. } \\
\text { - Reconocimiento de los logros de los miembros del equipo. } \\
\text { - Reconocimiento de las contribuciones de los demás. }\end{array}$ & \\
\hline \multicolumn{2}{|l|}{ Competencias funcionales } \\
\hline Organización & \multirow[b]{2}{*}{$\begin{array}{l}\text { No. de ítems: } 4 \\
\text { Cronbach } \alpha:, 826 \\
\text { Factorial: } 1 \text { factor } \\
\text { Varianza explicada: } 65,7 \% \\
\text { Sig. Bartlett: , oO० } \\
\text { KMO: ,795 }\end{array}$} \\
\hline $\begin{array}{l}\text { - Seguimiento de los procesos que hacen parte de las responsabilidades. } \\
\text { - Definición de tiempo y recursos necesarios para el desarrollo de proyectos y } \\
\text { programas. } \\
\text { - Coordinación de los procesos universitarios. } \\
\text { - Organización de los recursos de manera efectiva. }\end{array}$ & \\
\hline Planeación & \multirow{2}{*}{$\begin{array}{l}\text { No. de items: } 3 \\
\text { Cronbach } \alpha:, 757 \\
\text { Factorial: } 1 \text { factor } \\
\text { Varianza explicada: } 67,5 \% \\
\text { Sig. Bartlett: , ooo } \\
\text { KMO: }, 678\end{array}$} \\
\hline $\begin{array}{l}\text { - Establecimiento de cursos de acción para sí mismo y para los demás. } \\
\text { - Traducción de los objetivos estratégicos en planes prácticos y factibles. } \\
\text { - Anticipación de situaciones críticas y prevención con mecanismos para enfrentarlos. }\end{array}$ & \\
\hline
\end{tabular}




\begin{tabular}{|c|c|}
\hline Dirección & \multirow{2}{*}{$\begin{array}{l}\text { No. de items: } 3 \\
\text { Cronbach } \alpha:, 737 \\
\text { Factorial: } 1 \text { factor } \\
\text { Varianza explicada: } 66,6 \% \\
\text { Sig. Bartlett: , } 000 \\
\text { KMO: ,688 }\end{array}$} \\
\hline $\begin{array}{l}\text { - Reconocimiento de las capacidades de los integrantes del equipo. } \\
\text { - Desarrollo de habilidades y competencias de los subordinados. } \\
\text { - Diseño de estrategias para fortalecer el desarrollo de las competencias de los docentes } \\
\text { y personal administrativo. }\end{array}$ & \\
\hline Controlar & \multirow[b]{2}{*}{$\begin{array}{l}\text { No. de items: } 4 \\
\text { Cronbach } \alpha:, 815 \\
\text { Factorial: } 1 \text { factor } \\
\text { Varianza explicada: } 64,9 \% \\
\text { Sig. Bartlett: , Ooo } \\
\text { KMO: }, 779\end{array}$} \\
\hline $\begin{array}{l}\text { - Diseño e implementación de indicadores de gestión para el control y seguimiento. } \\
\text { - Monitoreo y control del uso de los recursos universitarios. } \\
\text { - Diseño e implementación de mecanismos de control para los avances de las tareas } \\
\text { asignadas. } \\
\text { - Supervisión en situaciones particulares de las actividades asignadas. }\end{array}$ & \\
\hline
\end{tabular}

Fuente: elaboración propia.

\section{Análisis de la información}

Las variables fueron tratadas con estadística descriptiva, en donde se resumieron las variables cuantitativas con el uso de la media, la desviación estándar, y los mínimos y máximos; y las cualitativas con las frecuencias relativas y porcentajes. Con el objetivo de identificar si existen diferencias estadísticamente significativas, se utilizó la prueba $t$ de Student para muestras independientes de acuerdo con criterios de normalidad evaluados con la prueba Shapiro Wilk.

\section{Resultados}

\section{Perfil sociodemográfico de los participantes y descriptivo de las instituciones}

Los participantes del estudio son en su mayoría hombres que dirigen principalmente cargos medios en las instituciones de educación superior. Esto contrasta con las mujeres, quienes se encuentran principalmente en cargos bajos de dirección, evidenciados en la Tabla 3. Las edades tanto de hombres como de mujeres son en promedio cercanas y se evidencia que las trayectorias de los hombres en los cargos directivos son mayores que las de las mujeres. Con relación al nivel de formación, tanto los hombres como las mujeres cuentan principalmente con título de magíster, como se observa en la Tabla 4.

Los participantes son en su mayoría directivos de universidades privadas, $61 \%$ de las cuales están acreditadas, en contraste con el $75 \%$ de acreditación de las públicas, que tienen en promedio mayor número de estudiantes, todo lo cual se refleja en la Tabla 5. Según los resultados, en las instituciones privadas existe mayor porcentaje de directivos en cargos altos y cargos medios, cuando se comparan con las públicas, como se observó en la Tabla 3.

\section{Análisis descriptivo de las competencias}

Los resultados de las competencias de los directivos universitarios evidencian que las que tienen mayor valoración fueron trabajo en equipo y liderazgo, mientras que las variables con menos valoración son control y planeación. Eso a su vez refleja una mayor importancia para las competencias comportamentales $(M=4,6)$ que para las funcionales ( $M$ $=4,4)$. En la Figura 1 se presentan los resultados descriptivos de todas las competencias. 
Tabla 3. Composición de los cargos según el género y la afiliación institucional

\begin{tabular}{|c|c|c|c|c|c|}
\hline & \multicolumn{2}{|c|}{ Género } & \multicolumn{2}{|c|}{ Tipo de institución } & \multirow{2}{*}{$\begin{array}{l}\text { Total } \\
\text { n (\%) }\end{array}$} \\
\hline & $\begin{array}{c}\text { Hombres } \\
n(\%)\end{array}$ & $\begin{array}{c}\text { Mujer } \\
n(\%)\end{array}$ & $\begin{array}{c}\text { Privada } \\
\text { n (\%) }\end{array}$ & $\begin{array}{c}\text { Pública } \\
\text { n (\%) }\end{array}$ & \\
\hline Cargos altos & $30(69,8)$ & $13(30,2)$ & $33(76,7)$ & $10(23,3)$ & $43(15,8)$ \\
\hline Cargos medios & $51(63,7)$ & $29(36,3)$ & $51(63,7)^{*}$ & $28(35,0)^{*}$ & $80(29,4)$ \\
\hline Cargos bajos & $79(53,0)$ & $70(47,0)$ & $79(53,0)$ & $70(47,0)$ & $149(54,8)$ \\
\hline Total & $160(58,8)$ & $112(41,2)$ & $163(59,9)$ & $108(39,7)$ & 272 \\
\hline \multicolumn{6}{|l|}{${ }^{*}$ Dato perdido } \\
\hline
\end{tabular}

Fuente: elaboración propia.

Tabla 4. Perfil sociodemográfico de los directivos según el género

\begin{tabular}{|l|c|c|}
\hline \multicolumn{1}{|c|}{ Caracteristica } & Hombre & Mujer \\
\hline Edad (años) & 53 & 50 \\
\hline Media & 32 & 33 \\
\hline Edad mínima & 82 & 70 \\
\hline Edad máxima & \multicolumn{2}{|l|}{} \\
\hline Antigüedad en el cargo (años) & 5,3 & 4,7 \\
\hline Media & $<1$ & 23 \\
\hline Antigüedad mínima & 32 & $42(37,5)$ \\
\hline Antigüedad máxima & $62(38,8)$ & $57(50,9)$ \\
\hline Nivel de formación $\boldsymbol{n}$ (\%) & $83(51,9)$ & $10(8,9)$ \\
\hline Doctor & $11(6,9)$ & $2(1,8)$ \\
\hline Magíster & $3(1,9)$ & $1(0,9)$ \\
\hline Especialista & $1(0,6)$ & \\
\hline Profesional & & \\
\hline Tecnólogo & \multicolumn{1}{|c|}{} \\
\hline
\end{tabular}

Fuente: elaboración propia.

Tabla 5. Características de las instituciones de afiliación

\begin{tabular}{|l|c|c|}
\hline \multicolumn{1}{|c|}{ Privada } & Pública \\
\hline Total instituciones & 163 & 108 \\
\hline Antigüedad de la institución (promedio en años) & 93 & 75 \\
\hline Número de estudiantes (promedio) & 14.745 & 26.261 \\
\hline Acreditación institucional n (\%) & $100(61,3)$ & $83(76,9)$ \\
\hline Sí & $63(38,7)$ & $25(23,1)$ \\
\hline No & & \\
\hline
\end{tabular}

Fuente: elaboración propia. 
Desde la perspectiva del género de los directivos, se encuentra que para las mujeres la competencia con mayor valoración es el trabajo en equipo, mientras para los hombres es el liderazgo. Para las mujeres el liderazgo ocupa el segundo lugar y la organización el tercero, mientras que para los hombres ocupan estos puestos el trabajo en equipo y la toma de decisiones y negociación, respectivamente. En ambos casos, el control es la competencia con menor valoración, como se observa en la Figura 2.

Figura 1. Descriptivos de las competencias directivas

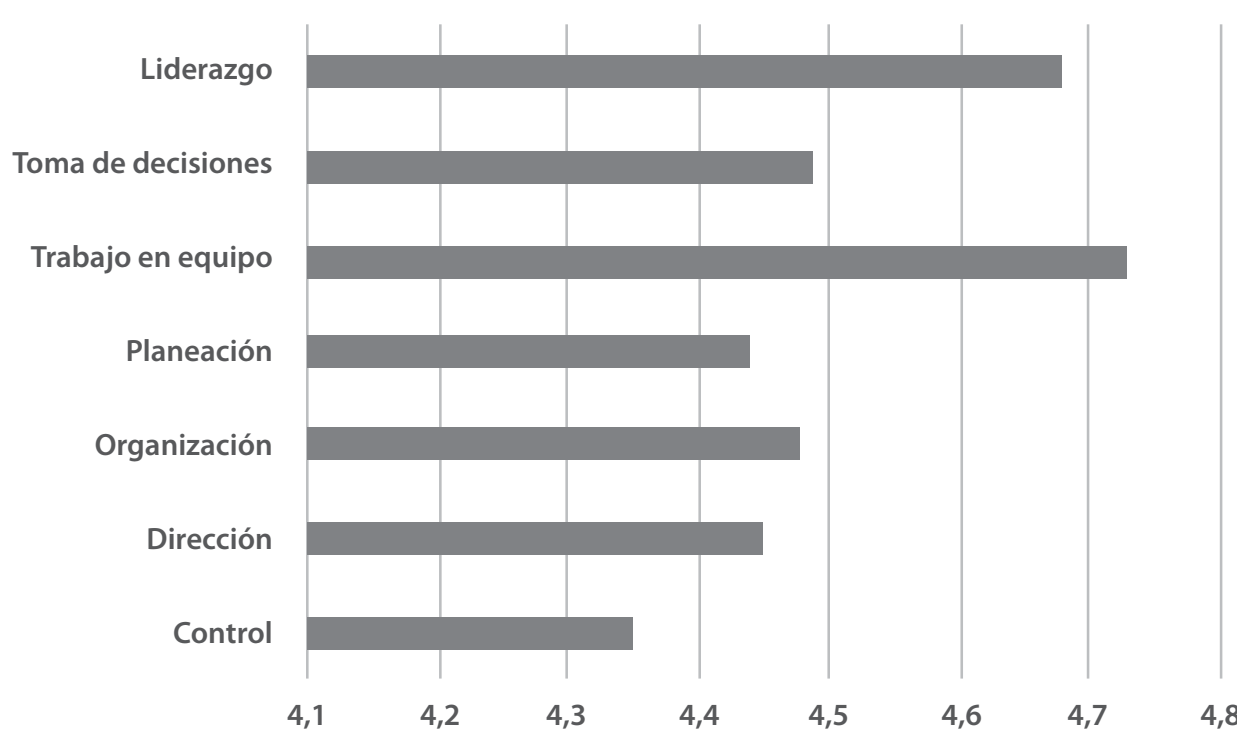

Fuente: elaboración propia.

Figura 2. Descriptivos de las competencias directivas según el género

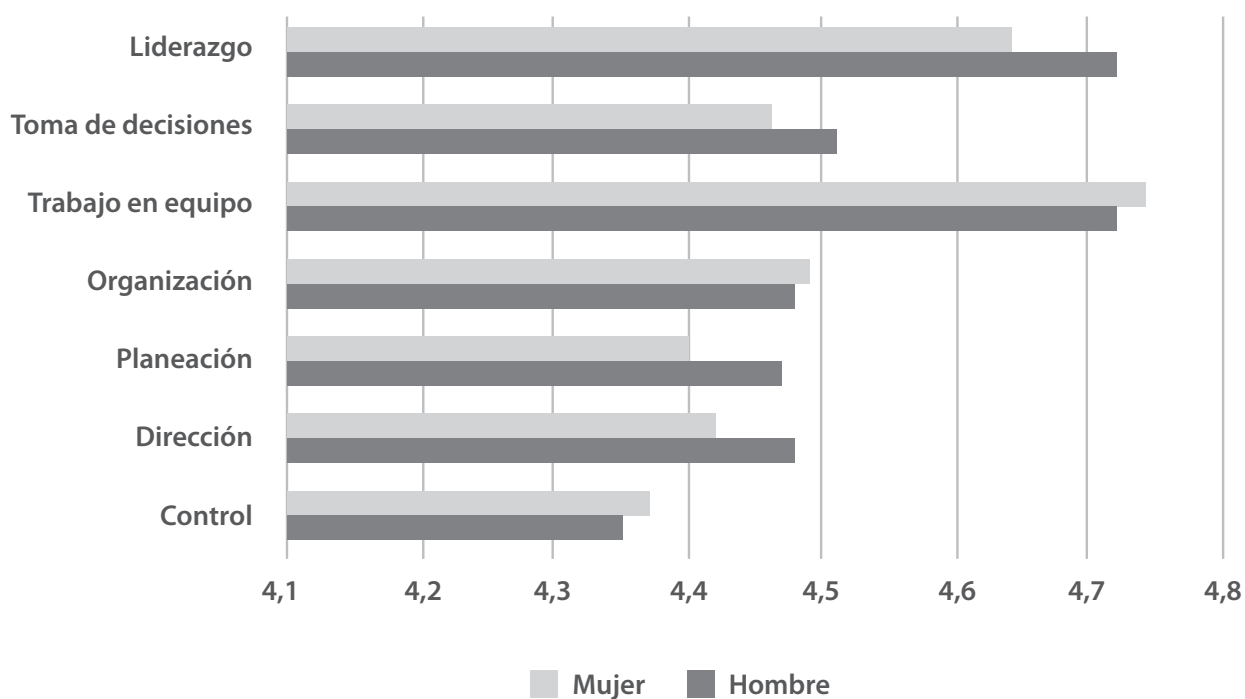

Fuente: elaboración propia. 
Para los directivos de universidades tanto públicas como privadas la competencia que tiene mayor relación con la gestión es el trabajo en equipo, seguida del liderazgo. En el caso de directivos de universidades públicas, la competencia con menor relación con la gestión fue el control y para los de universidades privadas la dirección. En la Figura 3 se presentan los promedios de las valoraciones de las competencias.

Los resultados evidencian que, para los cargos altos y cargos medios, la principal competencia identificada es el liderazgo. Para el caso de los cargos medios, también es el trabajo en equipo, que, a su vez, es la principal competencia identificada por los directivos de cargos bajos. Después del liderazgo, los cargos altos valoran las competencias de toma de decisiones y negociación y de trabajo en equipo, lo que implica que para este tipo de directivos las competencias funcionales tienen mayor peso en su gestión que las genéricas. Para los cargos medios, en segundo lugar, se encuentra la organización y en ter- cer lugar la planeación. En los cargos bajos, le sigue el liderazgo y la toma de decisiones y negociación, lo que también implica predominio de competencias comportamentales para estos cargos. Los resultados se presentan en la Figura 4.

\section{Análisis univariante}

Al evaluar las medias en los grados de correspondencia de las competencias con la gestión de los directivos, se encuentra que en ningún caso existen diferencias estadísticamente significativas. En la Tabla 6 se presentan los comparativos.

Al evaluar el grado de correspondencia de las competencias según el género del directivo en los cargos, se observa que solo existe diferencia estadísticamente significativa en la competencia de liderazgo para los cargos bajos ( $p<0,01)$, siendo mayor en los hombres $(M=4,7$; $D E=0,33)$ que en las mujeres $(M=4,6$; $D E=0,43)$. La información de estos resultados se presenta en la Tabla 7.

Figura 3. Descriptivos de las competencias directivas por institución de afiliación

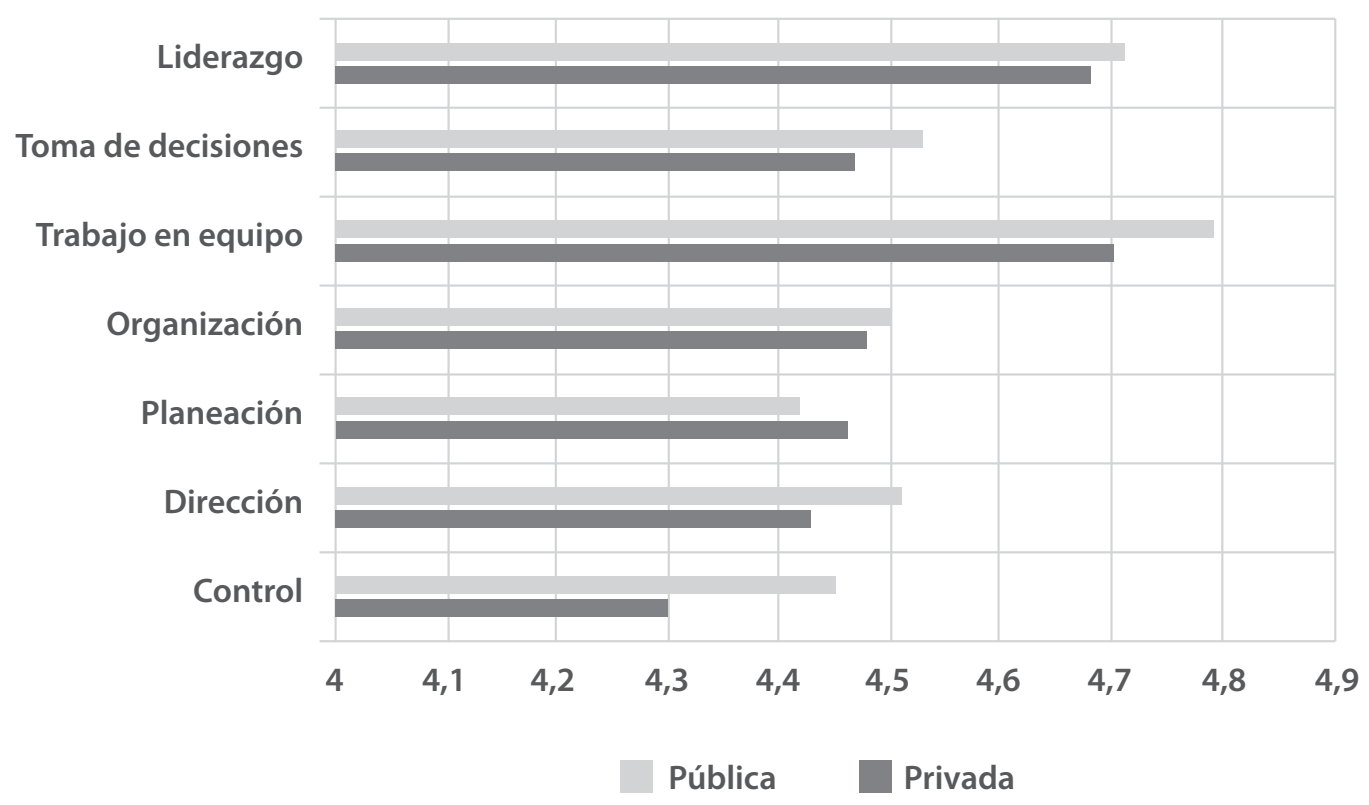

Fuente: elaboración propia. 


\section{Figura 4. Descriptivos de las competencias directivas según el tipo de cargo}

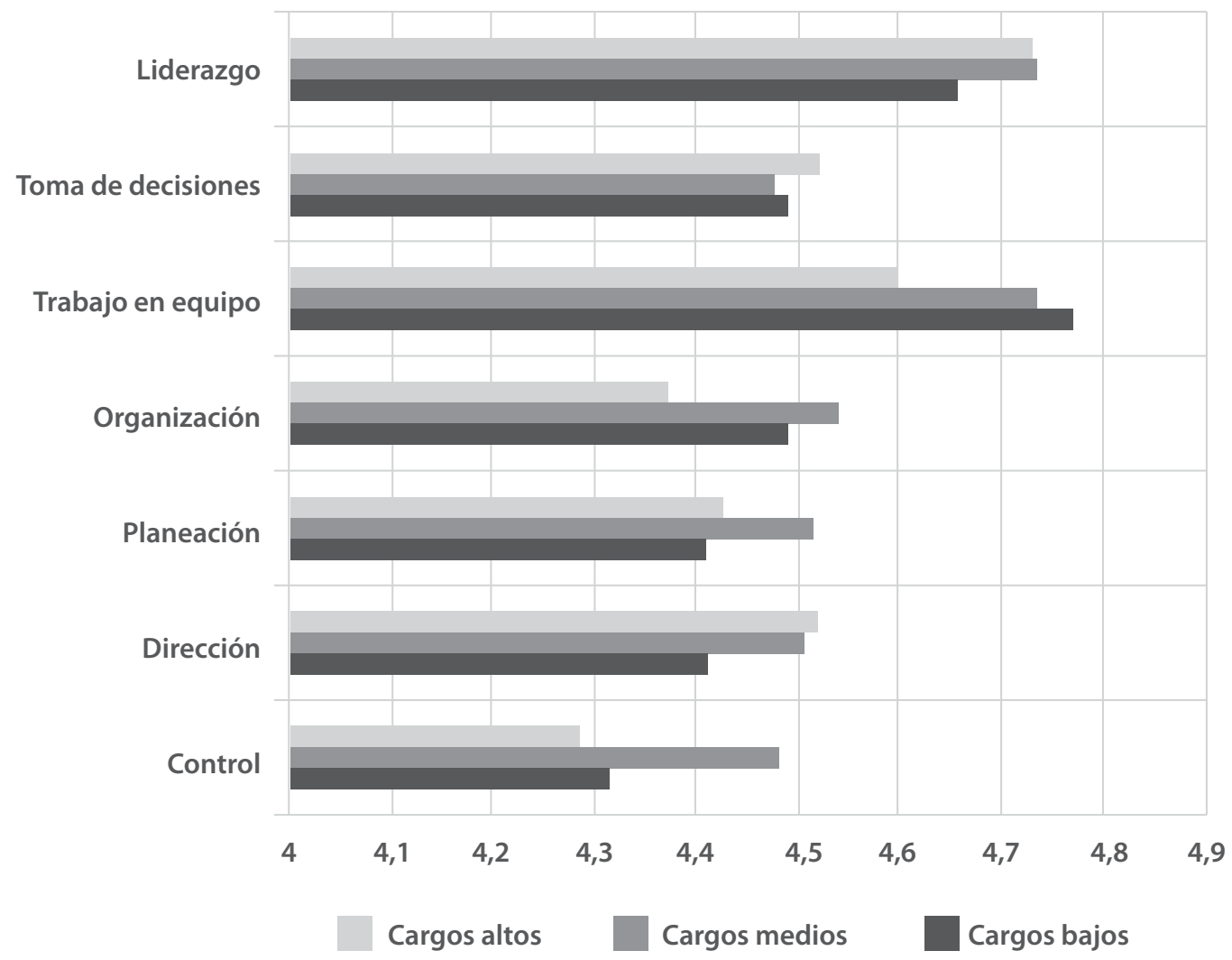

Fuente: elaboración propia

Tabla 6. Comparación de competencias por género del directivo

\begin{tabular}{|l|c|c|c|c|c|}
\hline & \multicolumn{2}{|c|}{ Hombre } & \multicolumn{2}{c|}{ Mujer } & \\
\hline & Media & Desviación estándar & Media & Desviación estándar & Significancia \\
\hline Liderazgo & 4,7 & 0,54 & 4,6 & 0,39 & 0,840 \\
\hline Toma de decisiones & 4,5 & 0,54 & 4,5 & 0,51 & 0,730 \\
\hline Trabajo en equipo & 4,7 & 0,47 & 4,7 & 0,33 & 0,635 \\
\hline Planeación & 4,5 & 0,54 & 4,4 & 0,50 & 0,638 \\
\hline Organización & 4,5 & 0,56 & 4,5 & 0,44 & 0,266 \\
\hline Dirección & 4,5 & 0,55 & 4,4 & 0,49 & 0,409 \\
\hline Control & 4,3 & 0,60 & 4,4 & 0,58 & 0,135 \\
\hline
\end{tabular}

Fuente: elaboración propia. 
ISSN 0123-1294 | e-ISSN 2027-5358 | Educ.Educ. Vol. 23. No. 4 | Noviembre-enero de 2021 | pp. 685-708

Universidad de La Sabana | Facultad de Educación

Tabla 7. Comparación de competencias en los cargos por género del directivo

\begin{tabular}{|c|c|c|c|c|c|}
\hline & \multicolumn{2}{|r|}{ Hombre } & \multicolumn{2}{|r|}{ Mujer } & \multirow[b]{2}{*}{ Significancia } \\
\hline & Media & Desviación estándar & Media & Desviación estándar & \\
\hline \multicolumn{6}{|l|}{ Cargos altos } \\
\hline Liderazgo & 4,7 & 0,74 & 4,8 & 0,17 & 0,174 \\
\hline Toma de decisiones & 4,5 & 0,75 & 4,6 & 0,28 & 0,160 \\
\hline Trabajo en equipo & 4,6 & 0,74 & 4,5 & 0,34 & 0,701 \\
\hline Planeación & 4,5 & 0,76 & 4,3 & 0,39 & 0,461 \\
\hline Organización & 4,4 & 0,78 & 4,4 & 0,37 & 0,215 \\
\hline Dirección & 4,6 & 0,8 & 4,4 & 0,33 & 0,145 \\
\hline Control & 4,3 & 0,76 & 4,4 & 0,44 & 0,597 \\
\hline \multicolumn{6}{|l|}{ Cargos medios } \\
\hline Liderazgo & 4,7 & 0,65 & 4,7 & 0,32 & 0,366 \\
\hline Toma de decisiones & 4,5 & 0,32 & 4,4 & 0,61 & 0,105 \\
\hline Trabajo en equipo & 4,7 & 0,41 & 4,7 & 0,36 & 0,971 \\
\hline Planeación & 4,5 & 0,52 & 4,5 & 0,5 & 0,560 \\
\hline Organización & 4,5 & 0,57 & 4,6 & 0,46 & 0,812 \\
\hline Dirección & 4,5 & 0,47 & 4,4 & 0,55 & 0,451 \\
\hline Control & 4,4 & 0,54 & 4,5 & 0,52 & 0,914 \\
\hline \multicolumn{6}{|l|}{ Cargos bajos } \\
\hline Liderazgo & 4,7 & 0,33 & 4,6 & 0,43 & $0,004^{*}$ \\
\hline Toma de decisiones & 4,5 & 0,47 & 4,4 & 0,49 & 0,925 \\
\hline Trabajo en equipo & 4,7 & 0,36 & 4,8 & 0,3 & 0,471 \\
\hline Planeación & 4,4 & 0,44 & 4,4 & 0,52 & 0,394 \\
\hline Organización & 4,5 & 0,43 & 4,5 & 0,44 & 0,957 \\
\hline Dirección & 4,4 & 0,46 & 4,4 & 0,49 & 0,635 \\
\hline Control & 4,3 & 0,58 & 4,3 & 0,62 & 0,665 \\
\hline
\end{tabular}

Fuente: elaboración propia.

Al igual que la evaluación de las competencias según el género del directivo, la evaluación según el tipo de institución de afiliación del directivo tampoco evidencia diferencias estadísticamente significativas, como se observa en la Tabla 8.

A pesar de que no existen diferencias estadísticamente significativas a la luz del tipo de afilia- ción institucional, cuando este comparativo es desagregado según el género del directivo, se observa que en las instituciones públicas existe una diferencia significativa en el caso de la competencia del liderazgo $(\mathrm{p}<0,05)$, siendo mayor en los hombres $(M=4,8 ; D E=0,32)$ que en las mujeres $(M=4,6 ; D E$ $=0,45)$, como se ve en la Tabla 9 . 
Tabla 8. Comparación de las competencias por institución de afiliación del directivo

\begin{tabular}{|l|c|c|c|c|c|}
\hline & \multicolumn{2}{|c|}{ Pública } & \multicolumn{2}{c|}{ Privada } & \\
\cline { 2 - 6 } & Media & Desviación estándar & Media & Desviación estándar & Significancia \\
\hline Liderazgo & 4,7 & 0,37 & 4,7 & 0,54 & 0,282 \\
\hline Toma de decisiones & 4,5 & 0,5 & 4,5 & 0,53 & 0,659 \\
\hline Trabajo en equipo & 4,8 & 0,32 & 4,7 & 0,46 & 0,388 \\
\hline Planeación & 4,4 & 0,48 & 4,5 & 0,55 & 0,854 \\
\hline Organización & 4,5 & 0,46 & 4,5 & 0,54 & 0,851 \\
\hline Dirección & 4,5 & 0,46 & 4,4 & 0,54 & 1,000 \\
\hline Control & 4,5 & 0,52 & 4,3 & 0,63 & 0,543 \\
\hline
\end{tabular}

Fuente: elaboración propia.

Tabla 9. Comparación de las competencias por género del directivo y afiliación institucional

\begin{tabular}{|c|c|c|c|c|c|}
\hline & \multicolumn{2}{|r|}{ Hombre } & \multicolumn{2}{|r|}{ Mujer } & \multirow[b]{2}{*}{ Significancia } \\
\hline & Media & Desviación estándar & Media & Desviación estándar & \\
\hline \multicolumn{6}{|c|}{ Instituciones públicas } \\
\hline Liderazgo & 4,8 & 0,32 & 4,6 & 0,45 & $0,013^{*}$ \\
\hline Toma de decisiones & 4,6 & 0,45 & 4,5 & 0,56 & 0,137 \\
\hline Trabajo en equipo & 4,8 & 0,29 & 4,8 & 0,35 & 0,123 \\
\hline Planeación & 4,5 & 0,49 & 4,4 & 0,47 & 0,439 \\
\hline Organización & 4,5 & 0,47 & 4,5 & 0,53 & 0,352 \\
\hline Dirección & 4,6 & 0,47 & 4,4 & 0,45 & 0,528 \\
\hline Control & 4,7 & 0,53 & 4,4 & 0,52 & 0,964 \\
\hline \multicolumn{6}{|c|}{ Instituciones privadas } \\
\hline Liderazgo & 4,7 & 0,63 & 4,7 & 0,37 & 0,250 \\
\hline Toma de decisiones & 4,5 & 0,37 & 4,5 & 0,46 & 0,549 \\
\hline Trabajo en equipo & 4,7 & 0,54 & 4,8 & 0,3 & 0,303 \\
\hline Planeación & 4,5 & 0,56 & 4,4 & 0,53 & 0,339 \\
\hline Organización & 4,5 & 0,6 & 4,5 & 0,43 & 0,347 \\
\hline Dirección & 4,4 & 0,58 & 4,4 & 0,47 & 0,465 \\
\hline Control & 4,3 & 0,63 & 4,4 & 0,62 & 0,602 \\
\hline
\end{tabular}

Fuente: elaboración propia. 
ISSN 0123-1294 | e-ISSN 2027-5358 | Educ.Educ. Vol. 23. No. 4 | Noviembre-enero de 2021 | pp. 685-708

Universidad de La Sabana | Facultad de Educación

En cuanto a las medias de las competencias según el cargo de dirección de los hombres y las mujeres, existen diferencias estadísticamente significativas solamente para el caso de las mujeres. Con relación a las competencias de los cargos de dirección de las mujeres, se observan en los cargos altos de dirección algunas diferencias estadísticamente significativas, cuando son evaluadas las medias del grado de correspondencia de las competencias con otros cargos (medios y bajos), como lo es para el liderazgo $(M=4,8 ; D E=0,17 ; p<0,01)$ y la dirección $(M=4,4 ; D E$ $=0,33)$. En la Tabla 10 se discriminan los resultados:
En los cargos medios se observa menor valoración de la competencia de toma de decisiones $y$ negociación ( $M=4,4 ; D E=0,61 ; p<0,05)$, la cual tiene una diferencia estadísticamente significativa al comparar con los cargos altos y bajos (Tabla 11).

Finalmente, se observa una diferencia estadísticamente significativa al comparar la valoración del liderazgo por parte de los cargos bajos $(M=4,6 ; \mathrm{DE}=$ $0,43)$ con la que hacen los altos y medios $(M=4,7$; DE $=0,28 ; p<0,01)$. En la Tabla 12 se presentan los comparativos de las medias de todas las competencias.

Tabla 10. Comparación de las mujeres directivas en los cargos altos

\begin{tabular}{|l|c|c|c|c|c|}
\hline & \multicolumn{2}{|c|}{ Cargos altos } & \multicolumn{2}{c|}{ Otros cargos } & \\
\cline { 2 - 6 } & Media & Desviación estándar & Media & Desviación estándar & Significancia \\
\hline Liderazgo & 4,8 & 0,17 & 4,6 & 0,41 & $0,003^{*}$ \\
\hline Toma de decisiones & 4,6 & 0,28 & 4,4 & 0,53 & $0,002^{*}$ \\
\hline Trabajo en equipo & 4,5 & 0,34 & 4,8 & 0,32 & 0,587 \\
\hline Planeación & 4,3 & 0,38 & 4,4 & 0,52 & 0,174 \\
\hline Organización & 4,4 & 0,44 & 4,5 & 0,45 & 0,264 \\
\hline Dirección & 4,4 & 0,33 & 4,4 & 0,33 & $0,059^{* *}$ \\
\hline Control & 4,4 & 0,44 & 4,4 & 0,6 & 0,308 \\
\hline$*$ p $\leq, 01 ; * * p \leq 0,05$ & & & & \\
\hline
\end{tabular}

Fuente: elaboración propia.

Tabla 11. Comparación de las mujeres directivas en los cargos medios

\begin{tabular}{|c|c|c|c|c|c|}
\hline & \multicolumn{2}{|c|}{ Cargos medios } & \multicolumn{2}{|c|}{ Otros cargos } & \multirow[b]{2}{*}{ Significancia } \\
\hline & Media & Desviación estándar & Media & Desviación estándar & \\
\hline Liderazgo & 4,7 & 0,32 & 4,6 & 0,41 & 0,170 \\
\hline Toma de decisiones & 4,4 & 0,61 & 4,5 & 0,47 & $0,039^{*}$ \\
\hline Trabajo en equipo & 4,7 & 0,36 & 4,8 & 0,32 & 0,854 \\
\hline Planeación & 4,5 & 0,5 & 4,4 & 0,50 & 0,471 \\
\hline Organización & 4,6 & 0,46 & 4,5 & 0,43 & 0,380 \\
\hline Dirección & 4,4 & 0,55 & 4,4 & 0,47 & 0,384 \\
\hline Control & 4,5 & 0,52 & 4,3 & 0,59 & 0,715 \\
\hline
\end{tabular}

Fuente: elaboración propia. 
Tabla 12. Comparación de las mujeres directivas en los cargos bajos

\begin{tabular}{|c|c|c|c|c|c|}
\hline & \multicolumn{2}{|c|}{ Cargos bajos } & \multicolumn{2}{|c|}{ Otros cargos } & \multirow[b]{2}{*}{ Significancia } \\
\hline & Media & Desviación estándar & Media & Desviación estándar & \\
\hline Liderazgo & 4,6 & 0,43 & 4,7 & 0,28 & $0,002^{*}$ \\
\hline Toma de decisiones & 4,5 & 0,49 & 4,5 & 0,54 & 0,610 \\
\hline Trabajo en equipo & 4,8 & 0,3 & 4,7 & 0,36 & 0,423 \\
\hline Planeación & 4,4 & 0,52 & 4,4 & 0,48 & 0,673 \\
\hline Organización & 4,8 & 0,44 & 4,5 & 0,44 & 0,938 \\
\hline Dirección & 4,4 & 0,49 & 4,4 & 0,49 & 0,666 \\
\hline Control & 4,3 & 0,62 & 4,5 & 0,5 & 0,401 \\
\hline
\end{tabular}

Fuente: elaboración propia.

\section{Conclusiones}

De acuerdo con la percepción de los directivos universitarios, se encontró que las competencias con mayor grado de identificación son el trabajo en equipo y el liderazgo. Cuando se comparan estos resultados según el género del directivo, se encuentra que para las mujeres la competencia con mayor correspondencia es el trabajo en equipo, mientras que para los hombres es el liderazgo. Para las valoraciones según la afiliación del directivo se encuentra también que para las instituciones públicas y privadas el trabajo en equipo es la competencia con mayor correspondencia. Desde el punto de vista de los cargos, se encuentran algunas diferencias: para los cargos bajos la competencia con mayor valoración es el trabajo en equipo; para los cargos medios trabajo en equipo y el liderazgo, y para los cargos altos, el liderazgo.

De acuerdo con los diferentes comparativos se concluye que las competencias con mayor valoración son el trabajo en equipo y el liderazgo, las cuales hacen parte de las competencias comportamentales. Si bien las medias son diferentes cuando se comparan desde el punto de vista del género, del tipo de institución y de los cargos directivos, solo para algunas competencias las diferencias son estadísticamente significativas. Este es el caso del liderazgo, cuando se compara según el género en los cargos bajos de dirección, siendo mayor valorado por los hombres que por las mujeres. Lo mismo ocurre con esta competencia cuando se evalúan las medias de hombres y mujeres en las instituciones públicas, siendo mayor en ellos.

En la evaluación de las medias de las mujeres en los distintos cargos también se encontraron diferencias estadísticamente significativas. Cuando las mujeres ocupan cargos altos de dirección tienen mayor valoración que las mujeres que están en cargos medios y bajos, en la competencia de liderazgo, toma de decisiones y dirección. Lo anterior corresponde con la evaluación de las medias cuando las mujeres que ocupan cargos medios, ya que se evidencia menor correspondencia en la toma de decisiones que en los cargos altos y bajos; y cuando las mujeres ocupan cargos bajos, el liderazgo tiene una media menor que para los cargos altos y medios.

El presente estudio encuentra, al igual que otras investigaciones, la importancia del liderazgo para la gestión universitaria (Casani y Rodríguez, 
2012; Mohd y Dola, 2009; Shahmandi et al., 2011; Spendlove, 2007; Zermeño et al., 2014). Así mismo, el estudio pone en evidencia la importancia de seguir aportando a la línea de investigación que aborda el género y el liderazgo en los contextos de educación superior, al evidenciar que existen diferencias estadísticamente significativas cuando se comparan las competencias de los hombres con las de las mujeres, y cuando estas comparaciones se dan según el cargo directivo. Con relación a este último punto, el estudio también concuerda con los hallazgos de otras investigaciones, al reconocer que para los cargos altos el liderazgo es la competencia más importante o con mayor correlación con las tareas de los directivos, la cual contrasta con los cargos bajos, donde se destaca el trabajo en equipo (Kloot, 2004; Mercer, 2009; Mohd y Dola, 2009; Pham et al., 2019; Spendlove, 2007; Wallace y Marchant, 2011).

El presente estudio se encuentra limitado por el tipo de muestra, que fue no probabilística, lo que restringió algunos análisis predictivos y métodos de proyección. Así mismo, dado que el instrumento de recolección de la información se concentró en competencias comportamentales y funciona- les evidenciadas en la literatura académica, para futuras líneas de investigación se sugiere utilizar instrumentos empleados en otras investigaciones y aplicar técnicas de recolección de la información cualitativas, como las entrevistas, las cuales permiten conocer con mayor profundidad las situaciones a las que se enfrentan los directivos universitarios en sus contextos particulares, y lo que ello demanda de su gestión.

Los hallazgos del estudio sugieren, para futuras investigaciones, determinar el efecto que tienen las características sociodemográficas y las características de las instituciones en las competencias de los directivos universitarios. Asimismo, se sugiere aportar más evidencia al estudio de directivos universitarios centrándose en el tema de las competencias, el cual es significativo, en la medida en que permite orientar planes y programas de formación para los docentes $u$ otros profesionales que se encuentren en cargos de dirección universitaria o deseen ocuparlos. Desde el punto del gobierno nacional, estos resultados permiten orientar o redefinir los lineamientos sobre los perfiles y requisitos de cargo para la dirección universitaria.

\section{Referencias}

Abdo, S.S.S. y Edgar, D. (2019). The role of leadership competencies in supporting the Al Nahda University for becoming a learning organization: a new qualitative framework of the DLOQ. International Journal of Business Administration, 10(2), 43-62. https://doi.org/10.5430/ijba.v10n2p43

Aguilar, L. F. (2006). Gobernanza y gestión pública. FCE.

Alles, M. A. (2007). Gestión por competencias: el diccionario. Granica.

Balbachevsky, B. (2015). The Latin American university model and the challenges posed by the reforms: Perspectives from the academics. En W. K. Cummings y U. Teichler (Eds.), The relevance of academic work in comparative perspective (pp. 239-252). Springer.

Balyer, A. y Özcan, K. (2017). Higher education administrators' managerial competency in Turkey. International Online Journal of Educational Sciences, 9(4), 917-929. https://doi.org/10.15345/iojes.2017.04.002 
Bedoya-Dorado, C., Murillo-Vargas, G. y González-Campo, C. H. (2020). ¿Académicos directivos o directivos académicos? Análisis de la construcción del sujeto directivo de instituciones de educación superior en Colombia. Espacios, 41(28), 271-289. https://www.revistaespacios.com/a20v41n28/a20v41n28p21.pdf

Barzelay, M. (2003). La nueva gerencia pública. Un acercamiento a la investigación y al debate de las políticas públicas. FCE.

Blenkinsopp, J. y Stalker, B. (2004). Identity work in the transition from manager to management academic. Management Decision, 42(3/4), 418-429. https://doi.org/10.1108/00251740410518903

Boyatzis, R. (1982). The competent manager: A model for effective performance. John Wiley \& Sons.

Casani, F. y Rodríguez-Pomeda, J. (2012). Percepciones de altos directivos universitarios españoles sobre sus necesidades formativas en competencias directivas. Revista de Ciencias Sociales, 18(1), 101-117. https://www. redalyc.org/pdf/280/28022785008.pdf

Castro, D. y Tomàs, M. (2011). Development of manager-academics at institutions of higher education in Catalonia. Higher Education Quarterly, 65(3), 290-307. https://doi.org/10.1111/j.1468-2273.2011.00490.x

Charria, V. H., Sarsosa, K. V., Uribe, A. F., López, C. N. y Arenas, F. (2011). Definición y clasificación teórica de las competencias académicas, profesionales y laborales. Las competencias del psicólogo en Colombia. Psicología desde el Caribe, 28, 133-165. https://www.redalyc.org/pdf/213/21320758007.pdf

CNA - Consejo Nacional de Acreditación (2020). Normatividad. https://www.cna.gov.co/1741/article-186370.html

Congreso de la República de Colombia (1992). Ley 30 de 28 de diciembre de 1992. Colombia. https://www.mineducacion.gov.co/sistemasdeinformacion/1735/articles-211884_Ley_30.pdf

Correia, M. A., Ney, F. R., Costa, J. R., Martins, K. C. y De Souza, F. R. (2017). O papel de gestor: Percepções de professores-gestores de uma universidade federal brasileira. Arquivos Analiticos de Politicas Educativas, 25(13), 1-37. https://dialnet.unirioja.es/servlet/articulo?codigo $=5846768$

Cuadrado, I., Navas, M. y Molero Alonso, F. (2004). El acceso de las mujeres a puestos directivos: género, contexto organizacional y estilos de liderazgo. Revista de Psicología General y Aplicada, 57(2), 181-192. https://dialnet. unirioja.es/servlet/articulo?codigo $=997864$

Deem, R. (2003). Gender, organizational cultures and the practices of manager-academics in UK universities. Gender Work and Organization, 10(2), 239-259. https://doi.org/10.1111/1468-0432.to1-1-00013

Eggins, H. (Ed.) (2017). The changing role of women in higher education. Academic and leadership issues. Springer. https://doi.org/10.1007/978-3-319-42436-1

Hellawell, D. y Hancock, N. (2001). A case study of the changing role of the academic middle manager in higher education: Between hierarchical control and collegiality? Research Papers in Education, 16(2), 183-197. https://doi.org/10.1080/02671520110037438 
ISSN 0123-1294 | e-ISSN 2027-5358 | Educ.Educ. Vol. 23. No. 4 | Noviembre-enero de 2021 | pp. 685-708

Universidad de La Sabana | Facultad de Educación

Hellriegel, D., Jackson, S. E. y Slocum, J. W. (2017). Administración. Un enfoque basado en competencias. Cengage Learning.

Henkel, M. (2000). Academic identities. Policy Change in higher education. Jessica Kingsley.

Hernández, R., Fernández, C.y Baptista, P. (2014). Metodología de la investigación (6 ed.). McGraw-Hill Interamericana.

Hoffmann, T. (1999). The meanings of competency. Journal of European Industrial Training, 23(6), 275-285. https:// doi.org/10.1108/03090599910284650

Kloot, L. (2004). Women and leadership in universities: A case study of women academic managers. International Journal of Public Sector Management, 17(6), 470-485. https://doi.org/10.1108/09513550410554760

Knox, C.C., Emrich, C. T. y Haupt, B. (2019). Advancing emergency management higher education: Importance of cultural competence scholarship. Journal of Emergency Management, 17(2), 111-117. https://doi.org/10.5055/ jem.2019.0403

Levy-Leboyer, C. (2002). Gestión de las competencias: cómo analizarlas, cómo evaluarlas y cómo desarrollarlas. Gestión 2000.

López, A. (2005). Los fundamentos de la nueva gestión pública: lógica privada y poder tecnocrático en el Estado mínimo. En M. Thwaites y A. López (Eds.), Entre tecnócratas globalizados y políticos clientelistas. Derrotero del ajuste neoliberal en el Estado argentino (pp. 71-9o). Prometeo.

Loyola, E., y Tristá, B. (2017). El directivo en la universidad contemporánea. Un enfoque de competencias. Revista Cubana de Educación Superior, 1, 4-14. http://scielo.sld.cu/scielo.php?script=sci_arttext\&pid $=$ So257-43142017000100001

Macarie, F. C., Hintea, C. y Mora, C. (2011). Gender and leadership. The impact on organizational culture of public institutions. Transylvanian Review of Administrative Sciences, 7(32), 146-156. https://www.researchgate.net/ publication/292452492_Gender_and_Leadership_The_Impact_of_Organizational_Culture_of_Public_Institutions

McClelland, D. (1973). Testing for competences rather than for intelligence. American Psychologist, 28, 1-14. https:// www.therapiebreve.be/documents/mcclelland-1973.pdf

McFarlane, B. (2011). The morphing of academic practice: Unbundling and the Rise of the para-academic. Higher Education Quarterly, 65(1), 59-73. https://doi.org/10.1111/j.1468-2273.2010.00467.x

MEN - Ministerio de Educación Nacional (2016). Resolución No. 09317 del 6 de mayo de 2016. https://www.mineducacion.gov.co/1759/articles-357038_recurso_1.pdf

Méndez, C. E. (2006). Metodología, diseño y desarrollo del proceso de investigación con énfasis en ciencias empresariales. Limusa. 
Mercer, J. (2009). Junior academic-manager in higher education: An untold story? International Journal of Educational Management, 23(4), 348-359. https://doi.org/10.1108/09513540910957444

Mohd, K. B. y Dola, K. (2009). Job competencies for Malaysian managers in higher education institution. Asian Journal of Management and Humanity Sciences, 4(4), 226-240. https://www.academia.edu/26098571/Job_ Competencies_for_Malaysian_Managers_in_Higher_Education_Institution

Moncayo-Orjuela, B. C. y Zuluaga-Goyeneche, D. (2015). Estilos de liderazgo en cargos universitarios. Estudio descriptivo con mujeres directivas. Panorama, 9(17), 74-84. https://journal.poligran.edu.co/index.php/panorama/article/view/793

OIT - Organización Internacional del Trabajo (1993). Formación profesional. Glosario de términos escogidos. Cinterfor/OIT.

Pérez-Ortega, G., Jiménez-Valdés, G. L.y Romo-Morales, G. (2016). Caracterización del liderazgo transformacional de los directivos de instituciones de educación superior. Caso de estudio en una universidad del departamento de Antioquia (Colombia). Entramado, 13(1), 48-61. https://doi.org/10.18041/entramado.2017v13n1.2513

Pham, T. Van, Nghiem, T. T., Nguyen, L. M. T., Mai, T. X. y Tran, T. (2019). Exploring key competencies of mid-level academic managers in higher education in Vietnam. Sustainability, 11(23), 2-13. https://doi.org/10.3390/ su11236818

Potgieter, I. L. y Coetzee, M. (2010). Management competencies in higher education: Perceived job importance in relation to level of training required. SA Journal of Human Resource Management, 8(1), 1-10. https://doi. org/10.4102/sajhrm.v8i1.306

Presidencia de la República (2020). Decreto 1083 de 2015 Sector de Función Pública. https://www.funcionpublica.gov.co/eva/gestornormativo/norma.php?i=62866

Rehbock, S. K. (2020). Academic leadership: Challenges and opportunities for leaders and leadership development in higher education. En M. Antoniadou y M. Crowder (Eds.), Modern Day challenges in academia (pp. 252-264). Edward Elgar.

Rybnicek, R. Leitner, K. H., Baumgartner, L. y Plakolm, J. (2019). Industry and leadership experiences of the heads of departments and their impact on the performance of public universities. Management Decision, 57(12), 3321-3345. https://doi.org/10.1108/MD-10-2018-1173

Schneijderberg, C. y Merkator, N. (2013). The new higher education professionals. En B. M. Kehm y U. Teichler (Eds.), The changing academy. The changing academic profession in international comparative perspective (pp. 53-92). Springer.

Shahmandi, E., Silong, A. D., Ismail, I. A., Samah, B. B. A. y Othman, J. (2011). Competencies, roles and effective academic leadership in world class university. International Journal of Business Administration, 2(1), 44-53. https://doi.org/10.5430/ijba.v2n1p44 
Shams, F. (2019). Managing academic identity tensions in a Canadian public university: The role of identity work in coping with managerialism. Journal of Higher Education Policy and Management, 41(6), 619-632. https:// doi.org/10.1080/1360080X.2019.1643960

Spendlove, M. (2007). Competencies for effective leadership in higher education. International Journal of Educational Management, 21(5), 407-417. https://doi.org/10.1108/09513540710760183

Telles, V. L., Meyer, V. y Falcão, D. (2019). Improvisation in higher education management: Coping with complexity and organizational dynamics. Global Journal of Flexible Systems Management, 20, 291-302. https://doi. org/10.1007/s40171-019-00215-8

Tomas, M., Durán, M. del M., Guillamón, C. y Lavié, J. M. (2008). Profesoras universitarias y cargos de gestión. Contextos Educativos, 11, 113-129. https://doi.org/10.18172/con.598

Vargas, A. R. y García, P. A. (2017). Competencias directivas, un reto para la educación superior. Academia y Virtualidad, 10(1), 11-22. https://doi.org/10.18359/ravi.2088

Wallace, M. y Marchant, T. (2011). Female administrative managers in Australian universities: Not male and not academic. Journal of Higher Education Policy and Management, 33(6), 567-581. https://doi.org/10.1080/136 oo80X.2011.621184

Whitchurch, C. (2013). Reconstructing identities in higher education. Routledge.

Winter, R. (2009). Academic manager or managed academic? Academicidentity schisms in highereducation.Journal of Higher Education Policy and Management, 31(2), 121-131. https://doi.org/10.1080/13600800902825835

Zermeño, L. O., Armenteros, M. C., Sologaistoa, A. G. y Villanueva, Y. (2014). Competencias directivas: su identificación para las instituciones de educación superior. Revista Global de Negocios, 2(4), 25-42. https://papers. ssrn.com/sol3/papers.cfm?abstract_id=2498601

Zuluaga-Goyeneche, D. y Moncayo-Orjuela, B. (2014). Perspectivas del liderazgo educativo: mujeres académicas en la administración. Suma de Negocios, 5(11), 86-95. https://doi.org/10.1016/S2215-910X(14)70023-0 